\title{
ENHANCING EAGLE PASS-PIEDRAS NEGRAS INTERNATIONAL BRIDGE DESIGN TO FUNCTION AS A TEMPORARY ACCOMMODATION FACILITY FOR ASYLUM SEEKERS
}

\author{
DOI: 10.18485/arh_pt.2020.7.ch45
}

\section{_ Chang Lu}

University of Pécs, Faculty of Engineering and Information

Technology, Pécs, Boszorkány út 2, 7624, cclu0820@gmail.com

\section{_ Ons Ben Dhaou}

University of Pécs, Faculty of Engineering and Information Technology, Pécs, Boszorkány út 2, 7624, cclu0820@gmail.com

\author{
_ Shaha Mazen Maiteh \\ University of Pécs, Faculty of Engineering and Information \\ Technology, Pécs, Boszorkány út 2, 7624, cclu0820@gmail.com
}

\author{
_ Tianyu Zhao \\ University of Pécs, Faculty of Engineering and Information \\ Technology, Pécs, Boszorkány út 2, 7624, cclu0820@gmail.com
}

\begin{abstract}
In May of 2019, a humanitarian crisis is intensifying along the borders of US-Mexico, almost 20000 people are waiting on Mexican borders to seek asylum in the United States, Mexico whish once a country of transit is now buckling under the demands of its new reality. US administration fails to absorb asylum seekers, organizations in Mexico have struggled to keep up with the influx of migrants. Along with that, the inhumane living conditions in migrant camps, systematic discrimination, and increased crime rate have made people restless for a response from the Centre of Border and Protection (CBP). This has led them to occupy streets, spaces near border walkways and bridges. Due to an increased number and drastic change of the social fabric, immigrants are a burden on city tourism and the city's safety. They are intruders and they are constantly facing racism, xenophobia and discrimination. Asylum seekers are slowly being rejected by both countries; between climate change and the chaos of global politics, the humanitarian crisis over the next decades will remain paramount, thoughtful design cannot prevent that inevitability, but it can alleviate some of the sufferings that asylum seekers will endure.
\end{abstract}

This research aims to solve the problem through enhancing the design of existing border bridges such as Eagle Pass-Piedras Negras International Bridge; which are essentially shared spaces, belonging either country. While migrant facilities limiting total intake, asylum seekers refuse to leave bridges, the essential design idea is to expand border bridges to become a temporary habitat for asylum seekers. This paper illustrates the design process of an immigrant respite centre, which functions as a temporary accommodation facility for 1500 asylum seekers designed on Eagle PassPiedras Negras International Bridge.

KEYWORDS _ co-living, asylum community, temporary accommodation, shelters 


\section{INTRODUCTION}

War, conflicts, economic circumstances or drastic environmental changes are causing a global situation of human displacement crisis. In the past century; the number of people seeking asylum has doubled, the refugee crisis is a paramount problem of today(International Organization for Migration 2020). According to the United Nations, the world is not capable of dealing with the accelerating demand for refugee camps (United Nations High Commissioner for Refugees 2019). In 2016 only 189,300 refugees were resettled from almost 70 million refugees, increasing the pressure on hosting communities to accommodate the refugees, forcing crisis management systems to fall apart faster. Asylum seekers seek refugee status in a safe country for better living standards and opportunities, however, when governments and institutions reject refugees, leaving them in life-threatening circumstances, it creates a burden and hostile environments which place asylum seekers in more harmful conditions than the ones they have escaped from. This same situation is happening now on the Mexican- American borders.

The "Zero Tolerance Policy" implemented in 2018 and "Metering" in 2019 has increased the Mexican- American borders humanitarian crisis(OFFICE OF INSPECTOR GENERAL Department of Homeland 2018). Mexican borders are hosting up to 19 thousand people seeking refugee status in the United States(Seelke 2020), settling in detention centres, camps and crowded shelters, facing hard-living medical conditions.

The main objective of the research is to demonstrate the design process of a respite centre over the Eagle Pass-Piedras Negras International Bridge to accommodate 1500 asylum seekers where they will temporarily stay for 1-2 months until their cases are heard by CBP (U.S. Customs and Border Protection). The design is based on creating a supportive social system within the respite centre by creating human interaction options and a facility that promotes co-living as a tool for collaborative community living. the design would provide asylum seekers with temporary accommodation, opportunities to plan their future, the proper health care and the right tools to enhance their skills to become productive and to be easily integrated within the community.

\section{Site}

The design site is the international bridge of Eagle Pass-Piedras Negras, the bridge is 600 meters long and 20 meters wide, the roadway is composed of two moving traffic lanes connecting the U.S. Customs and Border Protection - Eagle Pass Port of Entry on the east end with Plaza de Cobro - Puente Internacional Piedras Negras on the west end. The bridge has two pedestrian walkways of 1.8 meters on either side, it was constructed 15 meters above The Rio Grande river, the site coordinates are $-28^{\circ} 42^{\prime} 19.9^{\prime \prime} \mathrm{N} 100^{\circ} 30^{\prime} 42.5^{\prime \prime} \mathrm{W}$. The bridge is not commercial use but connects the Eagle Pass downtown shopping centres with the Piedras Negras downtown marketplace.

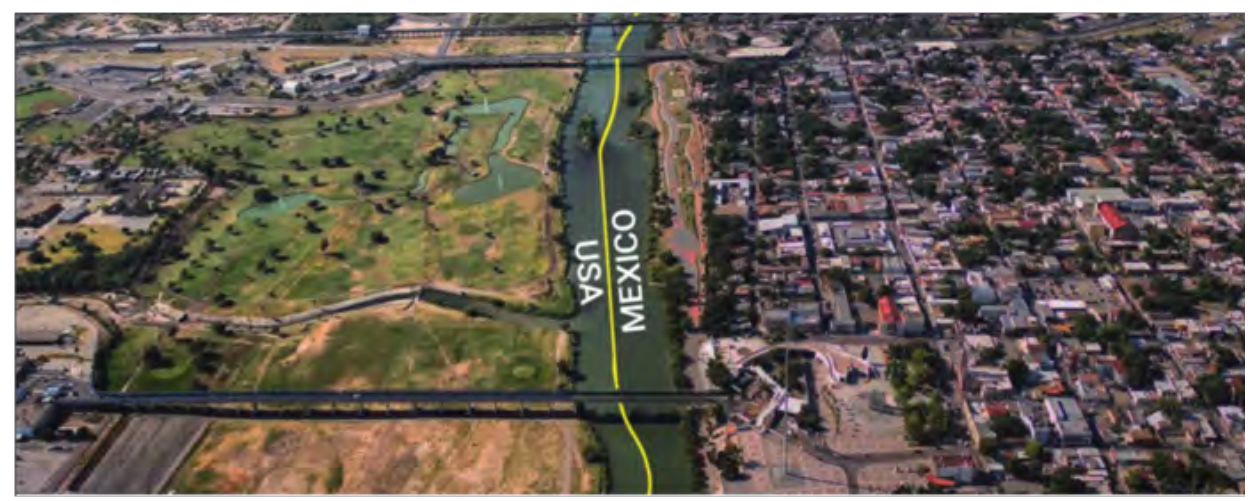

_ Figure 1:Overview of US-Mexico border near cities of Piedra Negras in Mexico and Eagle Pass in USA by (RODRÍGUEZ 2019) 
It was originally built in 1927 and reconstructed after it was damaged in a flood in 1954 (Transportation and Texas Department of Transportation 2015). The bridge operates between 7 am to $11 \mathrm{pm}$, the climate is semi-arid and hot. The site has a height restriction of 15 meters from the surface of the existing bridge. Piedras Negras is located on the Mexican side of the border and has a $62 \%$ crime rate, which is considered as a dangerous environment for immigrants seeking protection.

\section{METHODOLOGY}

Latin Americans tend to be highly group-oriented they consider family the core source of a community structure, therefore individual identity and essence values are defined by the family. The family mission is the protection of its members against the hardship of life, physically psychologically and financially, grounding a sense of belonging to the family which can be extended for grandparents, uncles, nephews, cousins and even people who are not biologically related such as sisters-in-law, and brothers-in-law.

When seeking asylum status; due to long document processing time, a large number of asylum seekers stray away from their values because they need the family's constant support system becoming victims of crime and discrimination.

The design concept is essentially based on recreating stong family-like connection between asylum seekers during their waiting time in the designed facility. The design promotes a modern coliving and cohabitation that combines two living patterns: pod chambers and extended family houses. Tailored for asylum seekers needs, the design is based on creating flexible and adaptable living units that can create a modern cluster of a single unit to be able to host a mixture of user-profiles, from a single adult, elderly couple, single parents with a child, or a family with 5 members. The design development was generated through 4 main phases: site accessibility, living scenario, inner community circulation, and architectural massing.

\section{RESULTS}

\section{Site Circulation}

The proposed site is Eagle Pass-Piedras Negras International Bridge, one of the main border bridges providing pedestrian and vehicle access route between Mexico and the United State. Asylum seekers are not allowed to enter both countries legally, making access andcirculation through the bridge extremely controlled and restricted. Therefore, the site access concept aims to keep the current functions of the bridge and introduce the accommodation as a ringed community surrounded by the main circulation, ensuring the safety and stability of the 1500 users, constraining any illegal community expansion.

Cutting both ends of the existing bridge and build the "No Man's Land" community on top of the existing bridge, the accommodation area is locked, consequently, the design will be an "island" attached to a designed traffic system connecting both lands. The existing bridge might need an additional structural support to bear the load of living unites, the new design suggests building a new pedestrian circulation path and a new car traffic lanes which have connections only with controlled access points on either side of the bridge away from new accommodation, the new bridge is added to the north edge of the exsisiting bridge, composed of two car lanes, each lane is 3-meter wide going in opposite directions, attached with an emergency lane of 2.3-meter wide. In addition, a 3-meter pedestrian sidewalk is added to the south edge of the traffic lanes, the new bridge is aligned to the exising bridge providing easy access and isolate the passage of asylum seekers from the flow of non stop border crossing traffic.Figure(02) illustrates the overall circulation of the designed bridge. 


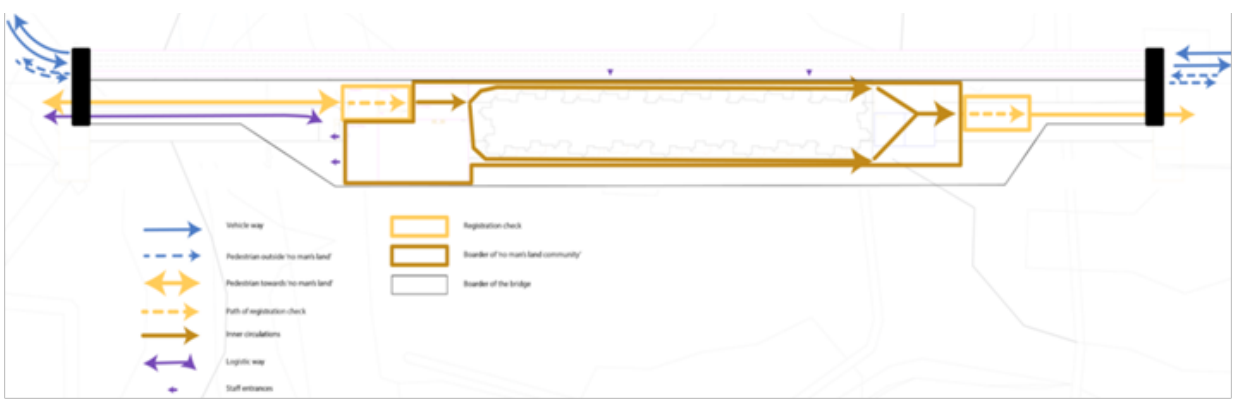

_ Figure 2:General illustration of inner and outer circulation with vehicles and pedestrian access points (Authors)

\section{Living scenarios}

Being forced to abandon their families and become immigrants, living on the borders of hostile environments; raises their possibility of being involved in criminal activity. The design concept aims to create a community support system like an extended family sitting which would improve the social interaction between immigrants and build a sense of belonging. But the economical burden of providing low cost, flexible and adaptive accommodation for asylum seekers plays a crucial role in the quality of the proposed accommodation solutions. Thereforeour proposed design introduces a hybrid modern living scenario which combines the Japanese pod hotels, with an extended family house. The hybrid design would be very efficient on both economic and social aspects. The pod compartment is a low-cost prefabricated lightweight structure which requires minimum floor area while providing personal privacy. On the other hand, the extended family house is culturally accepted in the perspective of potential users and build a new strong social relationship in record periods.

The accommodation configuration is developed into six main stages: First, a modular pod unit is designed to assure the privacy of individual users in the pod compartment of $2.5 * 1.5 * 1.7$ meters configuration providing a sleeping area and daily-use storage space. Then another pod unit is attached to the top of the base pod unit to optimize the use of storey height and floor area. Next, every 5 double-pod units are joined in a single cluster to form a nuclear family model analogy. Later every three nuclear family units are grouped to create an extended family unit module, sanitary, shared storage, and clean-shoe entrance are attached to the extended family cluster to serve 30 users as shown in figure (3).

Then the extended family units are multiplied and connected horizontally along with the linear form of the bridge platform in two-row formation creating 3 types of courtyards designed to host community gathering and maintain daylight accessibility to all family units. Finally, a second floor is attached with a slight horizontal shift to achieve the required population of 1500 user, allowing natural light access for all courtyard on the ground levelfigure (3).
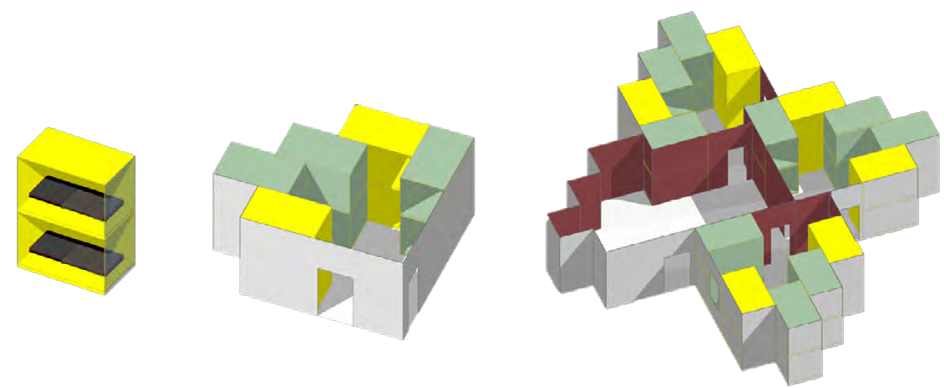

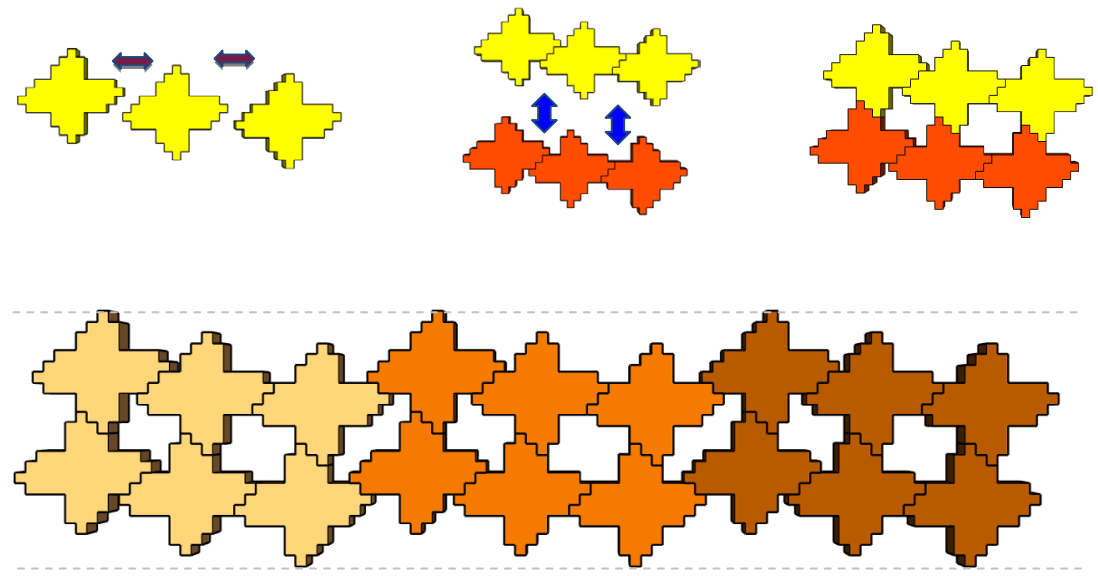

_ Figure 3:Modular development of accommodation scenario (Authors)

The extended-family module combination creates opportunities for social interaction, after studying different massing scenarios the final massing was created to assure the optimum use of the bridge span length and environmental possibilities of natural daylight and air ventilation figure (4).
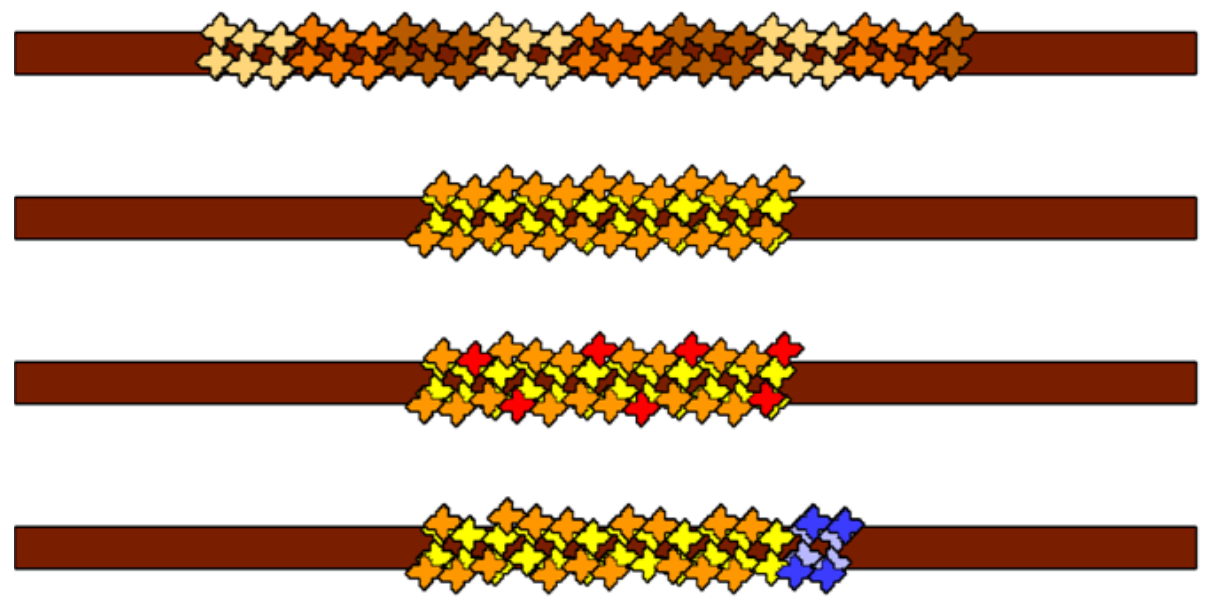

_ Figure 4: Development of accommodation layout, (a) One floor 50 unit per floor, (b) Two floors25 unit per floor, (c) Eliminate 6 units for second floor courtyards, (d) Add 6 unites to achieve population.(Authors)

\section{Inner circulation}

The project circulation is divided into two main circulation patterns. First, public circulation composed of horizontal and vertical circulation the direct horizontal circulation designed as main hallways and paths effected by the bridge linear geometry linking shared community spaces, the elongated form secure simple wayfinding which is needed for clear access and safety regulations. The vertical circulation is planned in a similar analogy utilising grand stairs leading to the first-floor level proving clear visual and physical accessibility for all users figure (5). Second, the private circulation connects accommodation unites to each other and to the shared courtyards, users can use indirect circulation routes affording interesting visual viewpoints and provide privacy for community's activities, enhance a sense of intimacy between users figure (6). 


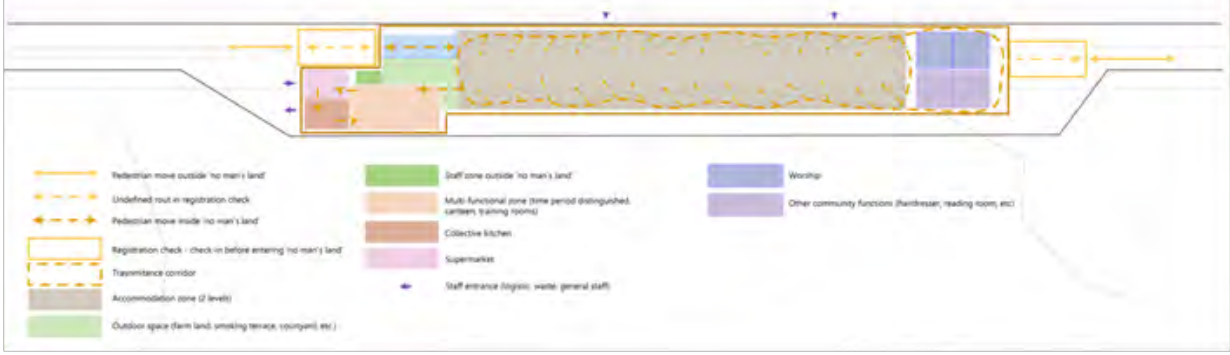

_ Figure 5: Public circulation pattern inside the asylum zone. (Authors)

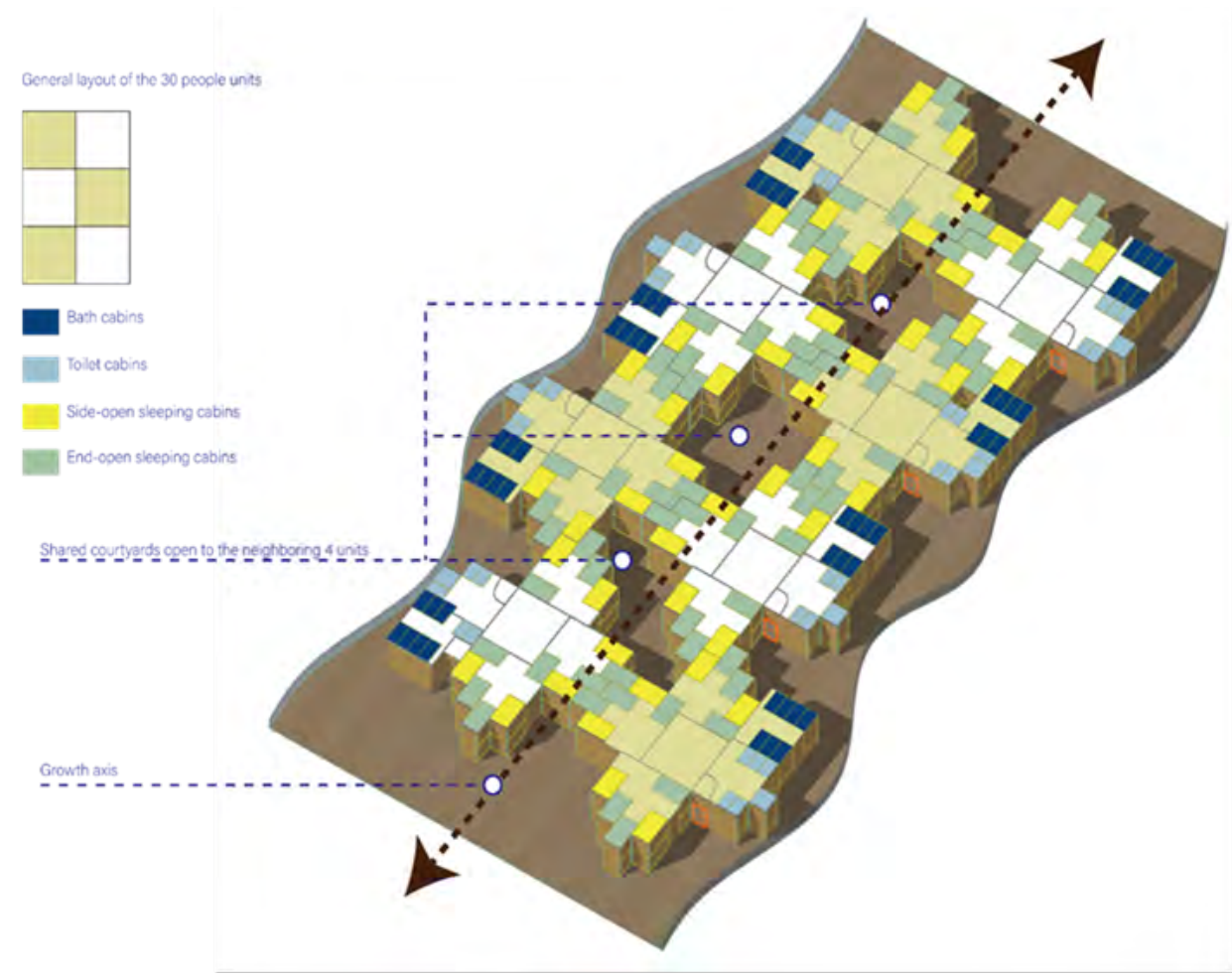

_ Figure 6: Asegement of accommodation private circulation. (Authors)

\section{Overall massing}

The massing concept is focusing on emphasising the longitudinal linear bridge structure as part of existing features, due to the harsh hot climatic conditions an exterior mesh structure is designed to cover the project using light-weight material that can withstand the environmental changes, by adding a double-skin layer of perforated sheets the overall massing show a rotating tube using organic curves adjusted to perfectly cover the geometry of the inner mass figure (7). 


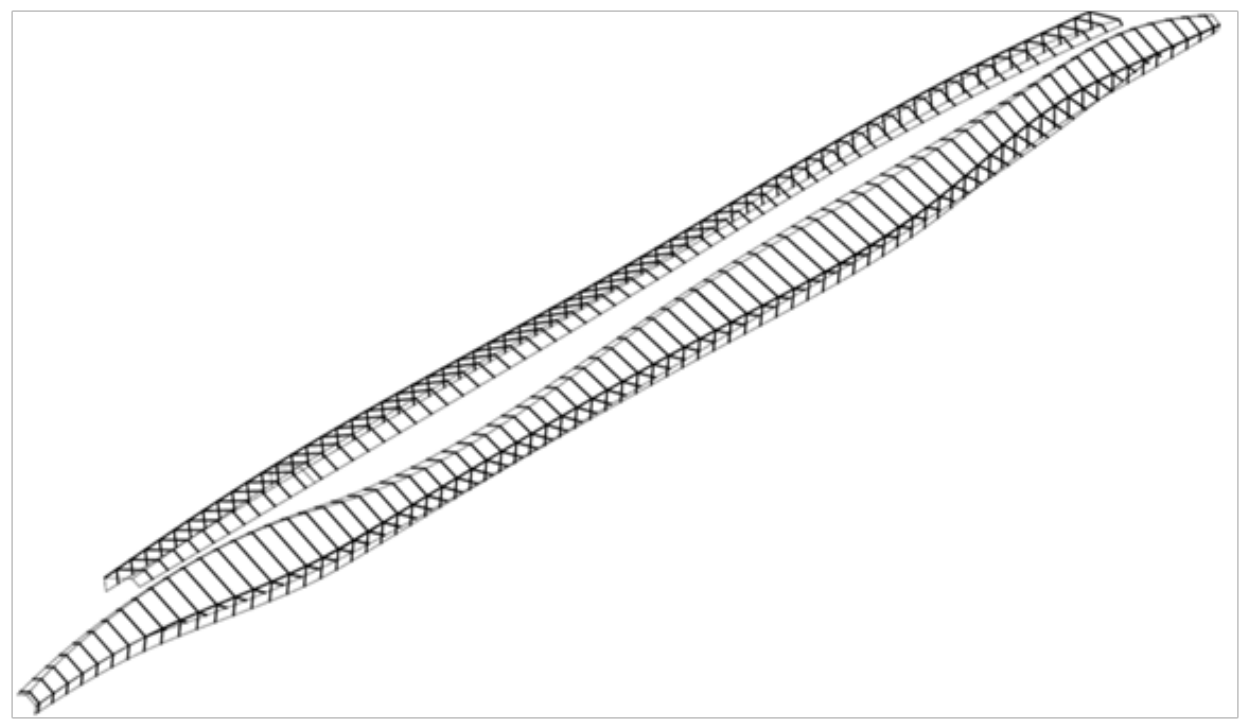

_ Figure 7: Rotating tube double-skin shell

\section{CONCLUSIONS}

With the acceleration of humanitarian crisis of forced immigration and climatic and environmental growing challenges, the need for creative examples and well-designed solutions becomes crucial and in need; because they have the potential to change the fateful future of a vast number of immigrants and asylum seekers over the globe, collective living community sharing can be implemented not only for an affordable city sitting but rather extended to be a valid rational solution for temporary asylum seekers, in addition to cutting construction and operational costs such living scenarios can help asylum seekers on a social and psychological level by rebuilding community trust feeling of belonging and support.

Developing collective living concepts that comply to such circumstances can be challenging and might have many limitations and constraints which should be considered on an early stage of the design, but if done in systematically it can be the start of a new era of dealing with forced immigration current failures and shortcomings.

\section{REFERENCES}

- International Organization for Migration. 2020. WORLD MIGRATION REPORT 2020. Geneva: International Organization for Migration. https://publications.iom.int/system/files/pdf/wmr_2020.pdf.

- OFFICE OF INSPECTOR GENERAL Department of Homeland. 2018. Special Report - Initial Observations Regarding Family Separation Issues Under the Zero Tolerance Policy. Special Report, Washington: Department of Homeland Security.

- RODRÍGUEZ, JOSUÉ. 2019. Perciben a Piedras Negras, Coahuila, como la frontera más segura de México. Vanguardia. 18 October. Accessed February 2020. https://vanguardia.com.mx/articulo/perciben-piedras-negras-coahuila-como-la-frontera-mas-segura-de-mexico.

- Seelke, Clare Ribando. 2020. "Mexico's Immigration Control Efforts." The Congressional Research Service. 19 February. Accessed March 3, 2020. https://crsreports.congress.gov/product/pdf/IF/IF10215. 
- Transportation, Texas Department of, and Texas Department of Transportation. 2015. TEXAS-MEXICO INTERNATIONAL BRIDGES AND BORDER CROSSINGS. Austin,Texas: Texas Department of Transportation.

- United Nations High Commissioner for Refugees. 2019. UNHCR PROJECTED GLOBAL RESETTLEMENT NEEDS 2020. RESTRICTED DISTRIBUTION 25th Annual Tripartite Consultations on Resettlement, GENEVA: United Nations High Commissioner for Refugees. https://www.unhcr.org/5d1384047.pdf. 